ICRES 2018: International Conference on Robot

Ethics and Standards, New York, USA, 20-21 August 2018.

https://doi.org/10.13180/icres.2018.20-21.08.023

\title{
REVISITING THE CONCEPT OF [WORK] IN THE AGE OF AUTONOMOUS MACHINES
}

\author{
MARIA ISABEL ALDINHAS FERREIRA \\ Centre of Philosophy of the University of Lisbon- Language, Mind and Cognition Group \\ Faculty of Arts and Humanities. University of Lisbon \\ and \\ Institute for Systems and Robotics, Instituto Superior Técnico. University of Lisbon
}

isabelferreira@letras.ulisboa.pt

\begin{abstract}
:
At the dawn of the overspread deployment of autonomous systems in most if not in every domain of life, the present paper revisits the concept of [work] claiming that the capacity for work is an essential human attribute. As it happens with all the attributes that define distinct life forms, this attribute has evolved all along human developmental history, as a consequence of their adapting and responding to distinct environmental physical conditions, to distinct modes of production and consequently to differentiated social and cultural contexts. Being an essential specific attribute of this social species and not the result of a temporary condition or state, [work], due to its generative power, is responsible for guaranteeing individual and collective subsistence throughout times, the evolution of distinct socio-economic frameworks, the emergence of rudimentary and progressively more sophisticated tools, the creation of culture and art forms and in so doing has been playing a determining role on the very evolutionary and developmental processes it emerges from.

Contemporary societies are becoming progressively more and more hybrid environments. This means environments where the physical is permeated by the digital, where human interaction is mediated by advanced forms of communication, where non-embodied and very soon also embodied forms of artificial intelligence coexist with natural intelligence ${ }^{1}$ where ultimately [work] in its intrinsic humaness is being replaced by task performing by artificial autonomous systems.

This present context and its predictable development in the near future ${ }^{2}$ demand the emergence of a deep awareness on the part of policy makers and from society in general so that technology remains a tool for enhancing [work], respecting its fundamental twofold dimension as: (i) a human generative endowment for the creation and transformation of reality (ii) a means for every human being to effectively be a part of this reality in all their dignity.
\end{abstract}

Keywords: Tools, Work, Technological Development, Hybrid World, Human Dignity

\section{Introduction}

In a significant number of species, the evolutionary and developmental process has proceeded according to three interconnected axes: (i) interaction ability, (ii) task performance ability, (iii)

\footnotetext{
${ }^{1}$ We are referring not just to the form of intelligence that characterises human cognition, but the ones that are inherent to all the other life forms

2 According to the International Federation of Robotics, more than 1.7 million industrial robots will have been installed in factories, worldwide, by 2020 and about 400 million workers around the globe will be displaced by 2030

https://ifr.org/ifr-press-releases/news/ifr-forecast-1.7-million-new-robots-to-transform-the-worlds-factories-by-20
} 
tool making ability ${ }^{3}$. The abilities represented by these three axes are made possible by a set of innate endowments that, though exhibiting a degree of variability among species in what relates their level of sophistication and complexity, represent a continuum that is horizontal to all of them. This way the capacity for communication, that the interaction ability subsumes, attains its highest degree of sophistication in human language, the same happening with the capacity for distributed task performing and the tool making capacity which are endogenous ${ }^{4}$ and define a continuum of progressive complexity throughout different species ${ }^{5}$. In what concerns human beings, these abilities are also the result of a learning process that takes place in society, that goes on throughout the individual's lifetime and that relies substantially on the accumulated experience of precedent generations and on the prevalent economic, social and cultural models. One of the substantial differences we can immediately identify when contrasting tool making in humans and in other species is the fact that while human tools have been evolving exponentially - with some tools exhibiting nowadays a considerable degree of potential autonomy that will require less or none human intervention - tool making among other species has remained rudimentary.

Tool making is inherently associated to the biological and the social and cultural evolution and development of human kind. Throughout the ages, human beings have modified or updated the inventions of precedent generations or those of other communities of tool makers and have also created new ones in order to achieve certain goals. From distinct modes of production specific scientific and technological innovations have emerged determining distinct working settings, distinct working tools.

Marx refers to tool use as an extension of the laboring body ${ }^{6}$ and views technologies as extensions of the human will domination over nature:

"Nature builds no machines, no locomotives, railways, electric telegraphs $[\ldots]$ These are products of human industry; natural material transformed into organs of the human will over nature...they are organs of the human brain created by the human hand" Marx 1993:706

Tool making and its natural evolution is inherently associated to the huge transformative and generative power resulting from the endogenous human working capacity.

\section{Artifacts for Work: Tools}

Human beings have been producing millions of artifacts, characteristic of particular civilizational frameworks and stages of development. As it happens with all the entities that populate the human world, each of these artifacts is value-laden, i.e., they have got an identity realized by a semantic value that defines and determines this same identity in the context of their use in particular social and cultural settings. But independently of this setting or context of use, there is a trait common to all artifacts. That feature is \{function\} which identifies the purpose an object fits in. It is the definition of this feature that allows us to distinguish [table] from [chair] or [glass] from [bottle]. And though the two first ones are comprehended in the

\footnotetext{
${ }^{3}$ The interaction ability, in fact, subsumes either (ii) or (iii). We make the distinction for purely analytical purposes

${ }^{4}$ Greenfield P. M. (1991). Language, tools, and brain: the development and evolution of hierarchically organized sequential behavior. Behav. Brain Sci. 14, 531-595

${ }^{5}$ Although tool use was for long been assumed to be a uniquely human trait, there is now much evidence that other species such as mammals, namely primates, birds, cephalopods also use more or less rudimentary tools. Cf. Shumaker, R.W., Walkup, K.R. and Beck, B.B., (2011) and Beck, B.B. (2013)

${ }^{6}$ Grigenti, Fabio (2016)
} 
broader category of [furniture] and the later in the broader categories of [container] and probably of [glassware] no one will, certainly, have any difficulty, under normal conditions, to distinguish the first from the others.

Tools are a particular subset of artifacts ${ }^{7}$. They share, with the broader category they belong to, the feature \{function\}, i.e. they are suited to a particular purpose, but their semantic specificity is realized by another fundamental feature. When looking at the definition of the concept [tool] in a language dictionary ${ }^{8}$ we read:

i. A tool ${ }^{9}$ is any instrument or piece of equipment that you hold in your hands in order to help you to do a particular kind of work. e.g., "workers downed tools in what soon became a general strike".

ii. A tool is also any object, skill, idea etc, that you use in your work or that you need for a particular purpose.

By analyzing these definitions we realize that the concept of [tool] is primarily associated to a working scenario and to the production/creation of a particular entity. This means that inherent to the semantics grounding the concept of [tool] is the trait \{cause an object, an event or a state to come into being, through physical and/or mental activity which is the essence of the concept of [work], weather the nature of this work is tangible or not. This fact can be easily foreseen when we think not only of a shoemaker handling their tools to create or repair a pair of shoes; a dressmaker making a dress, a carpenter making a chair, but also of a factory worker interacting with a machine to produce a particular piece, the farmer that drives a tractor to plough the field, the researcher that sits at the computer using a text processor to write a paper...

Tools can be seen as body extensions ${ }^{10}$ not only in the sense that they provide a means for accomplishing an action that the bare corporeal architecture was not able to perform by itself, but essentially because handling and/or operating any kind of tool always requires the adoption of specific protocols associated to the definition of new neural pathways that frequently comprehend the triggering out of specific motor programmes ${ }^{11}$ enabling particular postures or body movement. Tool handling is consequently responsible for the definition of neural pathways that will allow particular patterns of behavior to become typical and routinary, being, this way, instantly triggered out by specific contexts of use without depending on a reflexive attitude ${ }^{12}$.

\footnotetext{
${ }^{7}$ The definition of the concept of [tool] has been subject to different versions by researchers studying animal behavior.Hauser (2000) defines [tool] as an object that has been modified to fit a purpose or an inanimate object that one uses or modifies in some way to cause a change in the environment, thereby facilitating one's achievement of a target goal.

${ }^{8}$ Collins Cobuild English Language Dictionary. Collins Publishers. University of Birmingham 1988 ( $1^{\text {st }}$ edition)

${ }^{9}$ Emphases mine

${ }^{10}$ It is particularly interesting how some technological artifacts or technological tools are sometimes presented as extensions of the physical body. We recall on this purpose a small video opening a laptop computer produced by Texas Instruments in the early 90's - Texas Extensa- that stated: "Texas Extensa, an Extension of yourself"

${ }^{11}$ According to Young, R. (2003) the two fundamental human handgrips, first identified by J. R. Napier, and named 'precision grip' and 'power grip', represent a throwing grip and a clubbing grip, thereby providing an evolutionary explanation for the two unique grips, and the extensive anatomical remodelling of the hand that made them possible.

${ }^{12}$ Cf Ferreira (2014)
} 
This prosthetic nature of the tool is also addressed by Heidegger (1962) that refers how tools are taken into ways into which human beings enroll and project themselves into work practices as they "withdraw" and become "ready-to-hand"

Perhaps because of this nearly physiological extension, this quasi-symbiotic process, between a human being and a specific instrumental artifact, through which a specific entity is produced and comes into being, there is frequently a link of affective attachment that unites workers to their tools and to the produced works. This frequent affective attachment reflects itself in the care often revealed by workers in the maintenance and keeping of their tools ${ }^{13}$, in the way artisans have always carved out or just signed their names on the created object or in the sense of achievement and even pride manifested by those that have contributed to the coming into being of important realizations. This feeling was recently evident, for instance, in a newspaper interview to the workers that participated in the construction of the $25^{\text {th }}$ of April Bridge ( former Salazar Bridge) in Portugal, on the occasion of its 50 anniversary $^{14}$. According to António Rosa, one of these workers, the construction of this bridge, the biggest in Europe at that time, was a real challenge to everyone and it came out becoming a kind of second home to those deeply committed to their construction. With more than 40 years dedicated first to its building and then to its maintenance, this worker confessed that he still kept some of the tools he used then, namely a brush.

\section{Work as a Human Endowment}

Different ideological perspectives, distinct epistemological frameworks ${ }^{15}$ have converged on recognizing the uniqueness of [work] as a human endowment and its essential character in the definition of what to be human means.

To Marx (1968), [work] is the unique means through which human beings objectify their existence and come into being. It is this essential objectivation that sustains human condition and is the essence of humanity.

In fact when we reflect on the process through which individual identity is shaped we realize that it develops according to a succession of social circles ${ }^{16}$, starting in infancy, with the very small circle of close family members, and progressively broadens to others circles ( friends and acquaintances, school/academic circle, working/professional circle...) that partially overlapping define the individual's essence. In this process of identity formation, which Ferreira $(2007,2011)$ has compared to the process of formation of a pearl, the working/professional circle is fundamental for the definition of the role(s) the individuals will play in the social tissue and the way they will participate and act on it. What the individual is depends in fact on what s/he does, i.e., depends on the nature of their contribution, of their work embedded in the specific social context they belong to at a given historical time.

Another fundamental perspective on the essential character of this endowment in the definition of humaness is the Encyclica Laborem Exercens (14 $4^{\text {th }}$ September 1981). This encyclical, written by Pope John Paul II, is part of the larger body of Catholic social teaching tracing its origin back to Pope Leo XIII's 1891 encyclical Rerum Novarum. The Encyclica Laborem Exercens highlights the fact that the capacity for work is an essential human feature

\footnotetext{
${ }^{13}$ We recall on this purpose the particular attachment an hairdresser revealed towards her set of high specialized scissors, which she had acquired when becoming a professional and uses in her daily practice

$14 \mathrm{https}$ //www.sabado.pt/portugal/detalhe/conhece-o-dono-da-ponte-25-de-abril

${ }^{15} \mathrm{Cf}$ on this purpose Marx (1968) and John Paul II (1981)

${ }^{16}$ Cf Ferreira, (2007) (2011)
} 
that cannot be comparable by its intrinsic characteristics to the performing of certain tasks by other species in order to subsist.

"Work is one of the characteristics that distinguishes man from the rest of creatures, whose activity for sustaining their lives cannot be called work [....] it bears a particular mark of man and of humanity, the mark of a person operating within a community of persons. "(ibidem:1)

As the encyclical points out [work] is universal in the sense that it embraces "all human beings, every generation, every phase of economic and cultural development" and it is simultaneously a process that takes place within each human being, a personal narrative acknowledged by the conscious subject. Consequently it develops along two fundamental inseparable and complementary dimensions:

i. An objective dimension

ii.A subjective dimension

Its objective dimension relates to its generative and transformative power through which human beings act on the surrounding environment- "dominating nature"17, "subduing the earth"18 - and by so doing creating with the effort of their bodies and the intelligence of their intellects the necessary conditions for their "being" throughout the dynamics of an existential historical time.

"[....]there thus emerges the meaning of work in an objective sense, which finds expression in the various epochs of culture and civilization".(ibidem, 2)

This objective dimension is the tangible or non-tangible existential imprint registered not only by each society but by each of its individual members, from the most notorious to the most anonymous, since individual and collective existence and progress depend on the coordinated action and work of each and all in the different domains of human life.

John Paul II points out that [work] has an ethical value of its own, which clearly and directly remains linked to the fact that the one who carries it out is a person, a conscious and free subject.

"Working at any workbench, whether a relatively primitive or an ultramodern one, a man can easily see that through his work he enters into two inheritances: the inheritance of what is given to the whole of humanity in the resources of nature, and the inheritance of what others have already developed on the basis of those resources, primarily by developing technology, that is to say, by producing a whole collection of increasingly perfect instruments for work"(ibidem:6)

On the other hand, the subjective dimension relates to the consciousness every worker must acquire of their personal narrative and of the importance of their individual role, their contribution in a collective process to which all individual efforts converge. It is in its inherent humanity that resides the dignity of [work]:

"through work man not only transforms nature, adapting it to his own needs, but he also achieves fulfilment as a human being and indeed, in a sense, becomes "more a human being". (ibidem:9)

\section{When Tools Become Autonomous Machines: The Ontological Shift}

\footnotetext{
${ }^{17} \operatorname{Marx}(1968)$

${ }^{18}$ Laborem Exercens 1981
} 
Technological development has resulted and results from the [work] of many thousands, throughout multiple generations, from their creativity and accumulated experience, aiming at producing the necessary conditions to liberate individuals from the toil frequently associated to hard work, promoting individual well-being and society's development, improving life conditions, eradicating poverty and disease, assuring defense against eventual threats. The huge technological development brought by the digital revolution and ICT technologies with the progressive introduction of different forms of artificial intelligence ${ }^{19}$ in the means of production and in society in general - the 4IR - will cause an impact that is even more impressive than that brought by the first industrial revolution. Contemporary societies are in fact becoming progressively more and more hybrid environments. This means environments where the physical is permeated by the digital, where human interaction is mediated by advanced forms of communication, where non-embodied and very soon also embodied forms of artificial intelligence coexist with natural intelligence where ultimately [work], in multiple contexts and domains, is being replaced by task performing by autonomous systems.

Laying aside the evident differences inherent to the distinct stages of development that characterize the momentum of the present and those of the past technological revolutions, perhaps the most important feature brought about by the present one is that of the ontological shift of the concept of [tool]. In fact, so far, either hand tools or machine tools were manipulated or operated by human beings, depending on human skill and on their will. However [tools] are becoming progressively more and more independent from human control. By introducing forms of artificial intelligence in the means of production, by endowing machines with a form of intelligence that assigns them the capacity to operate and perform tasks independently of any form of human supervision, technology is in fact producing not tools but entities to which can easily be assigned the status of workers.

Martins,M. (2011: 18) refers to this as "a technological mutation, that ceases to be instrumental and conceived as an extension of the human arm but merges with human being, producing the very arm and threatening to produce the whole being" 20 .

More than the predicted huge unemployment ${ }^{21}$ - that in our opinion can be reverted or at least minimized by implementing the adequate social and political measures necessary to anticipate its negative impacts- e.g., prequalifying and training workers in order to their resetting- it is the potential expropriation of the generative and transformative power from human "hands/minds" that can become an existential problem.

\footnotetext{
19 “Artificial intelligence (AI) refers to systems that display intelligent behaviour by analysing their environment and taking actions - with some degree of autonomy - to achieve specific goals.-

AI-based systems can be purely software-based, acting in the virtual world (e.g. voice assistants, image analysis software, search engines, speech and face recognition systems) or AI can be embedded in hardware devices (e.g. advanced robots, autonomous cars, drones or Internet of Things applications".in

COMMUNICATION FROM THE COMMISSION TO THE EUROPEAN PARLIAMENT, THE EUROPEAN COUNCIL, THE COUNCIL, THE EUROPEAN ECONOMIC AND SOCIAL COMMITTEE AND THE COMMITTEE OF THE REGIONS Artificial Intelligence for Europe \{SWD(2018) 137 final\}

${ }^{20}$ My translation

${ }^{21}$ Andy Haldane, chief economist at the Bank of England. predicted, in 2015, that 15 million jobs in the UK, roughly half of all jobs, were under threat from automation. He pointed out that the first industrial revolution had occurred in the middle of the 18th century and the second in the latter half of the 19th century. The third industrial evolution the era of information technology - appeared to have resulted in an intensification of trends seen in the first two: "a hollowing-out of employment, a widening distribution of wages and a fall in labour's income share".

https://www.theguardian.com/business/2015/nov/12/robots-threaten-low-paid-jobs-says-bank-of-england-chiefeconomist
} 
Hal Varian, chief economist at Google, predicted the future in the following terms: " The future is simply what rich people have today. The rich have chauffeurs. In the future, we will have driverless cars that chauffeur us all around. The rich have private bankers. In the future, we will all have robo-bankers [...] One thing that we imagine that the rich have today are lives of leisure. So will our future be one in which we too have lives of leisure, and the machines are taking the sweat? We will be able to spend our time on more important things than simply feeding and housing ourselves?"22

These words come, in a way, nearly in line with the prediction made John Maynard Kaynes in Economic Possibilities for our Grandchildren (1930: I) ${ }^{23}$ :

"My purpose in this essay [....] is not to examine the present or the near future, but to disembarrass myself of short views and take wings into the future. What can we reasonably expect the level of our economic life to be a hundred years hence? What are the economic possibilities for our grandchildren?

[...] We are being afflicted with a new disease of which some readers may not yet have heard the name, but of which they will hear a great deal in the years to come--namely, technological unemployment. This means unemployment due to our discovery of means of economizing the use of labour outrunning the pace at which we can find new uses for labour. [....]But this is only a temporary phase of maladjustment. All this means in the long run that mankind is solving its economic problem.

I would predict that the standard of life in progressive countries one hundred years hence will be between four and eight times as high as it is to-day [....] Yet there is no country and no people, I think, who can look forward to the age of leisure and of abundance without a dread. For we have been trained too long to strive and not to enjoy. [...] For many ages to come the old Adam will be so strong in us that everybody will need to do some work if he is to be contented $[\ldots]$ Three-hour shifts or a fifteen-hour week may put off the problem for a great while. For three hours a day is quite enough to satisfy the old Adam in most of us!"

Kaynes was correct in at least three of his main points:

-Unemployment due to the discovery of means of economizing the use of labour outrunning the pace at which one can find new uses for labour.

-That US economy has nearly grown 8 times the standard living in 1930.

- The need to balance a life with sufficient leisure time with the intrinsic need of the human being to produce and create, ironically referred as the "old Adam in most of us"

In fact it can easily be forseen how a non-productive existence, where human beings are deprived of an active contribution by intelligent machines, would lead to human psychological and physical degeneracy in a life devoid of purpose and dignity.

Reflecting on the complex equilibrium demanded by the relationship between human beings and machines, Gehlen(1940),(1957) refers to this relationship as a form of human empowerment. In his opinion machines do not limit human faculties as they are modeled on them but take them to a higher level. The fact that they can exalt human capacity to take physical action on our environment, even to the point of enabling new and unnatural functions (such as human flight), goes to show that machines are capable of forming part of a manmachine assembly for the purpose of going beyond boundaries previously believed impossible to overcome.

\footnotetext{
${ }^{22}$ https://www.ft.com/content/4329a987-9256-3059-b36f-1aba9338b800
} 
Also referring metaphorically to the nature of this equilibrium, namely in what concerns present technology, Collins Sebastian (2018) refers that:

"Ironman isn't ironman without the suit, but the suit has no power without the man. That is the future of robotic development, people and robots, working together hand-in-hand to accomplish more than we ever thought would be possible"

On his hand, Paul Jones, professor of information science at the University of North Carolina, Chapel Hill, claims that future artificial intelligence (AI) will do well at enhancing human well-being:

"Humans need tools. Humans need and want augmentation. And as the saying goes 'First we make our tools, then our tools form us.' Since the first protohuman, this has been true".

\section{Conclusions}

In What New Jobs do We See Ahead?(2016:37), Elizabeth Curmi refers that in the past, automation and technological progress have not made human labour obsolete and society managed to adapt by creating new jobs to compensate for the loss of labour. As she points out, "in 1900, $41 \%$ of the US workforce was employed in agriculture; however by the year 2000 , that share had fallen to $2 \%$, mostly due to mechanisation of the sector. In the developed world, industrialisation moved people into factories and then moved them out again into services. Throughout these changes the number of jobs has always increased. US employment increased from 1950 to 2014, and the unemployment rate in $2015(5 \%)$ is returning back to its average after the financial recession of 2008/2009"

Though today's newer technology sectors have not provided the same opportunities, particularly for less educated workers, as the industries that preceded them we cannot but agree that "technology eliminates jobs, not work" 24

As Curmi points out, "what is clear is that technology has already changed the way we work and will continue to do so [...].At all skill levels, most jobs in demand will be characterised by non-routine tasks which are not easily replaced by technology or organisational change.

We can conclude by saying that in a hybrid world, [work] will also have a hybrid nature resulting from the use of intelligent tools functioning in conjunction with natural intelligence toward the achievement of human goals. A hybrid reality where human beings will hopefully not aim to subdue or dominate Nature or their peers, but aim to be One with Nature and the rest of Humanity.

\section{References:}

Beck, B., (1980). Animal Tool Behaviour: The Use and Manufacture of Tools by Animals Garland STPM Pub.

Curmi, E What New Jobs do We See Ahead?in Carl Benedikt Frey, Michael Osborne and Craig Holmes Technology at Work, v2.0 The Future Is Not What It Used to Be, 2016. Oxford Martin School. Citi GPS: Global Perspectives \& Solutions. available at: https://www.oxfordmartin.ox.ac.uk/downloads/reports/Citi_GPS_Technology_Work_2.pdf

Communication From The Commission To The European Parliament. The European Council, The European Economic and Social Committee and the Committee of the Regions. Artificial Intelligence for Europe $\{\operatorname{SWD}(2018) 137$ final $\}$

${ }^{24}$ Why are there still so many jobs? The History and Future of Workplace Automation, Journal of Economic Perspectives, Vol. 29, No. 3 pp 3-30. 
Ferreira, M.I.A. (2007, 2011) On Meaning: Individuation and Identity. Cambridge Publishers

Gehlen, Arnold. 1940. Der Mensch seine Natur und seiene Stellung in der Welt . Berlin: Junker und Dünnhaupt.

Gehlen, Arnold. 1957. Die seele im technischen Zeitalter . Hamburg: Rowohlt Taschenbuch Verlag. Jünger, Friedrich Georg. 1956. Die Perfektion der Technik . Frankfurt a. M: Klostermann

Grigenti, Fabio (2016) Marx, Karl- From Hand Tool to Machine Tool, in Existence and Machine. The German Philosophy in the Age of Machines ( 1870-1960). Springer https://www.springer.com/cda/.../9783319453651-c2.pdf..

DOI 10.1007/978-3-319-45366-8_2.

Hauser, M. (2000) The Evolution of Communication. MIT Press

Heidegger, M., (1962) Being and Time. Translated from Sein und Zeit $7^{\text {th }}$ edition, Max Niemeyer Verlag. Blackwell Publishing Limited

Keynes, J. M. , (1930) Economic Possibilities for our Grandchildren http://www.econ.yale.edu/smith/econ116a/keynes1.pdf

Martins, M., L., (2011) Crise no Castelo da Cultura: Das Estrelas para os Écrans. https://repositorium.sdum.uminho.pt/bitstream/1822/29167/1/CriseCastelodaCultura.pdf

Marzke M. W. (2013) Tool making, hand morphology and fossil hominins . Philosophical Transactions of the Royal Society B. Biological Sciences. Royal Society Publishing Published 7 October 2013.DOI: $10.1098 /$ rstb.2012.0414

http://rstb.royalsocietypublishing.org/content/368/1630/20120414\#ref-list-1

Marx, Carl. 1867. Das Kapital https://www.marxists.org/archive/marx/works/download/pdf/CapitalVolume-I.pdf

Sebastian, C. (2018) Robotics and Millenials available at https://usblog.softbankrobotics.com/robotsand-millennials-joining-forces-to-change-the-future-of-work (August 2018)

Shumaker, R.W., Walkup, K.R. and Beck, B.B., (2011). Jump up to: $\underline{\underline{b}} \underline{\boldsymbol{c}}$ in Animal Tool Behavior: The Use and Manufacture of Tools by Animals Johns Hopkins University Press, Baltimore

Sikka, Sonia (2018) Heidegger Moral and Politics, questioning the Shepherd of Being.Cambridge University Press

Stout D. (2011) Stone toolmaking and the evolution of human culture and cognition. Philos Trans R Soc Lond B Biol Sci. 2011 Apr 12; 366(1567): 1050-1059.

doi: 10.1098/rstb.2010.0369. https://www.ncbi.nlm.nih.gov/pmc/articles/PMC3049103/

Tinbergen, Niko (1953). The Study of Instinct. Oxford, Clarendon Press.

Young, R. W. ( 2003) Evolution of the human hand: the role of throwing and clubbing. J Anat. 2003 Jan; 202(1): 165-174.

doi: 10.1046/j.1469-7580.2003.00144.x https://www.ncbi.nlm.nih.gov/pmc/articles/PMC1571064/ 